SHORT COMMUNICATION

\title{
COMPARATIVE ANALYSIS OF SPLIT-WINDOW ALGORITHMS FOR ESTIMATING SOIL TEMPERATURE
}

\author{
Leonardo Vera ${ }^{1 *}$, Juan C. Parra ${ }^{2}$, Luís Morales ${ }^{3}$, Cristián Mattar ${ }^{3}$ and Emilio \\ Jorquera-Fontena ${ }^{4}$ \\ ${ }^{1}$ Escuela de Agronomía. Pontificia Universidad Católica de Valparaíso. Casilla 4059, Valparaíso, \\ Chile. ${ }^{2}$ Departamento de Ciencias Físicas, Facultad de Ingeniería, Ciencias y Administración, \\ Universidad de La Frontera. Casilla 54-D, Temuco, Chile. ${ }^{3}$ Departamento de Ciencias \\ Ambientales y Recursos Naturales Renovables, Facultad de Ciencias Agronómicas. Universidad \\ de Chile. Casilla 1004 Santiago, Chile. ${ }^{4}$ Programa de Doctorado en Ciencias de Recursos \\ Naturales. Universidad de La Frontera. Casilla 54-D, Temuco, Chile. \\ *Email: leonardo.vera@ucv.cl
}

\begin{abstract}
The ability to estimate soil temperature (Ts) from satellite information is highly useful, since this is one of the main input variables in various models designed for estimating biophysical parameters. A comparative analysis is made of various Split-Window algorithms used to estimate soil temperature from data provided by the Advanced Very High Resolution Radiometer (AVHRR) sensor on board of satellites of the National Oceanic and Atmospheric Administration (NOAA). The algorithms compared are those proposed by: Prata and Platt (1991); Uliveri et al. (1992); Sobrino et al. (1993); Caselles et al. (1997); Sobrino and Raissouni (2000). The temperature estimates were validated with data of the soil temperature in situ recorded in a data logger installed in a meteorological station belonging to La Araucanía Region, Chile. The results showed that the algorithm proposed by Sobrino and Raissouni (2000) come the closest to the in situ data. However, there are no statistically significant differences between the different algorithms evaluated.
\end{abstract}

Keywords: AVHRR-NOAA Sensor, meteorological station.

\section{INTRODUCTION}

Obtaining soil temperature (Ts) is of great use as an equilibrium indicator in soilatmosphere system and other biophysical parameters. Normally, the soil temperature is measured by using thermistors, but the cost of evaluating large geographical areas is usually high and time-consuming. The solution for these drawbacks arises with the development of infrared technology and later use on board artificial satellites. However, one of the biggest problems measurements of soil temperature from satellites is the combined action of perturbations due to atmospheric water vapor and the variability in the emissivities of different soil coverings (Morales and Parra, 2002). 
The need to implement algorithms to correct this effect introduced by the earth's emissivity and the water vapour in the atmosphere has led to the development of various methodologies, where Split-Window method has been one of the best-validated (Sobrino et al., 1993; Caselles et al., 1997; Sobrino and Raissouni, 2000; Sobrino et al., 2004).

The objective of the present communication is to apply and compare different Split-Window algorithms to estimate soil temperature from data provided by the AVHRR sensor on board the NOAA satellite, in order to find the best fit with data generated in situ.

\section{MATERIALS AND METHODS}

\section{Soil temperature measurement}

The soil temperature measurements were taken at hourly intervals, using one thermistor LI-COR buried at a depth of one centimeter and calibrated in the range -10 to $50{ }^{\circ} \mathrm{C}$ (mean squared error of 0.06 $\left.{ }^{\circ} \mathrm{C}\right)$. The thermistor was connected to a meteorological station located in the Institute of Agricultural ResearchCarillanca, Chile (INIA-Carillanca) $\left(38^{\circ} 41^{\prime} \mathrm{S} ; 2^{\circ} 25^{\prime} \mathrm{W} ; 200\right.$ m.a.s.l), between October 2003 and January 2004. The data were registered in a data logger LI-1000 (LI-COR Inc., USA).

The study zone is characterized by a temperate climate (Rouanet, 1983), flat topography (slopes of $0-25 \%$ ) and soils derived from modern volcanic ash (Andisol), Vilcún soil Serie (Tosso, 1985).

\section{Obtaining and selecting NOAA images}

Images were used from the NOAA 16 satellite in the visible and thermal infrared spectrum bands, obtained at not cost from the Comprehensive Large Arraydata Stewardship System (CLASS). The data base of images was chosen because it coincided with the dates of the field measurements (October 2003 and January 2004). Images were selected only for cloudless days in order to avoid image perturbation. A total of 62 images were reviewed, from which 18 were selected and subjected to a geo-referencing process. The identified pixel (size is 1 $\mathrm{km}^{2}$ ) corresponded to INIA-Carillanca meteorological station location.

\section{Algorithms implementation}

The Split-Window algorithms selected correspond to those proposed by: Prata and Platt (1991), Uliveri et al. (1992), Sobrino et al. (1993), Caselles et al. (1997) and Sobrino and Raissouni (2000) (Table 1).

The implementation of the various algorithms assumes the availability of the following information: brightness temperatures in bands 4 and 5, mean emissivity, spectrum variation of emissivity, and water vapour content. All these variables are associated to the pixel where the thermistor is located.

Radiometric temperatures in bands 4 and 5 of the AVHRR were obtained using the Calibrate Data module of the ENVI programme (version 4.0). Mean emissivity and spectrum variation were estimated by application of the threshold method, as described by Carlson and Ripley (1997). Finally, data from atmospheric water vapor were obtained from Morales and Parra (2002).

\section{Statistical analysis}

To compare the soil temperature data measured in situ with those obtained by each of the Split-Window algorithms, a linear regression equation was calculated between the observed $(\mathrm{X})$ and simulated (Y) values. The parameters of these equations were evaluated by proposing simultaneous hypothesis tests for the 
Table 1. Split-Window algorithms. $\mathrm{T}_{4}$ and $\mathrm{T}_{5}$ are brightness temperatures $\left({ }^{\circ} \mathrm{K}\right)$ in bands $4(10.3$ $11.3 \mu \mathrm{m})$ and $5(11.5-12.5 \mu \mathrm{m}) ; \varepsilon=\left(\varepsilon_{4}+\varepsilon_{5}\right) / 2$ and $\Delta \varepsilon=\varepsilon_{4}-\varepsilon_{5}$ are the mean emissivity and spectrum variation of emissivity in bands 4 and 5 of the AVHRR-NOAA sensor; $W$ is the water vapour content $\left(\mathrm{g} \mathrm{cm}^{-2}\right)$.

\begin{tabular}{|c|c|}
\hline Authors & Split-Window algorithm \\
\hline Prata and Platt, 1991. (P)* & $T_{s}=3.45 \frac{\left(T_{4}-T_{0}\right)}{\varepsilon_{4}}-2.45 \frac{\left(T_{5}-T_{0}\right)}{\varepsilon_{5}}+40 \frac{\left(1-\varepsilon_{4}\right)}{\varepsilon_{4}}+273$ \\
\hline Ulivieri et al., 1992. (U) * & $T_{s}=T_{4}+1.8\left(T_{4}-T_{5}\right)+48(1-\varepsilon)-75 \Delta \varepsilon$ \\
\hline Sobrino et al., 1993. (S1)* & $T_{s}=T_{4}+\left\lfloor 1.06+0.46\left(T_{4}-T_{5)}\right\rfloor\left(T_{4}-T_{5}\right)+53\left(1-\varepsilon_{4}\right)-53 \Delta \varepsilon\right.$ \\
\hline Caselles et al., 1997. (C) * & $\begin{array}{c}T_{s}=T_{4}+\left[1+0,58\left(T_{4}-T_{5}\right)\right]\left(T_{4}-T_{5}\right)+C(1-\varepsilon)-D(\Delta \varepsilon)+0,51 \\
C=(0,190 W-0,103) T_{4}-67 \mathrm{~W}+107 \\
D=(0,100 \mathrm{~W}+1,118) T_{4}-68 \mathrm{~W}-163\end{array}$ \\
\hline $\begin{array}{l}\text { Sobrino and Raissouni, } \\
\text { 2000. (S2) * }\end{array}$ & $\begin{array}{c}T_{s}=T_{4}+\left[1,40+0,32\left(T_{4}-T_{5}\right)\right]\left(T_{4}-T_{5}\right)+C(1-\varepsilon)-D(\Delta \varepsilon)+0,83 \\
C=57-5 \mathrm{~W} \\
D=161-30 \mathrm{~W}\end{array}$ \\
\hline
\end{tabular}

* Indicates the abbreviation used subsequently for each algorithm

intercept $(\mathrm{Ho}: \mathrm{a}=0)$ and the slope $(\mathrm{Ho}: \mathrm{b}=$ 1) using Student's " $t$ " test and a P-value $\leq 0.05$ (Steel and Torrie, 1988). In addition, the root mean squared error

(RMSE) of the prediction was calculated with the result being expressed in percentage units of the average value obtained in the real observations (Rabat, 1995).

\section{RESULTS}

Figure 1 shows modeled and measured data in order to evaluate algorithms performance. When the ratio between the estimated Ts $\left({ }^{\circ} \mathrm{C}\right)$ and the $\mathrm{T}$ in situ $\left({ }^{\circ} \mathrm{C}\right)$ is calculated, a significant equation is obtained $(\mathrm{P}<$ 0.00001 ) at a confidence level of $99 \%$, with a mean standard error of $2.57^{\circ} \mathrm{C}$.

When we carry out hypothesis tests on the values of the intercept and the slope in the algorithms for each case, we were able to conclude that these do not differ from the values zero and one, respectively. Table 2 shows the results of the regression equations obtained and the main statistics associated, which are: $b=$ intercept; $\mathrm{m}=$ slope; $\mathrm{r}^{2}=$ coefficient of determination adjusted from the regression; RMSE $=$ root mean squared error of the prediction in percentage terms; and $\mathrm{P}=$ level of significance.

The variance analysis of the means comparison test shows a P-value of 0.9413 , which is greater than 0.05 , indicating that the differences between the means of the algorithms used are not statistically significant, with $95 \%$ confidence.

\section{DISCUSSION}

It is well known that the superficial soil temperature retrieval from satellite observations has been ongoing for 


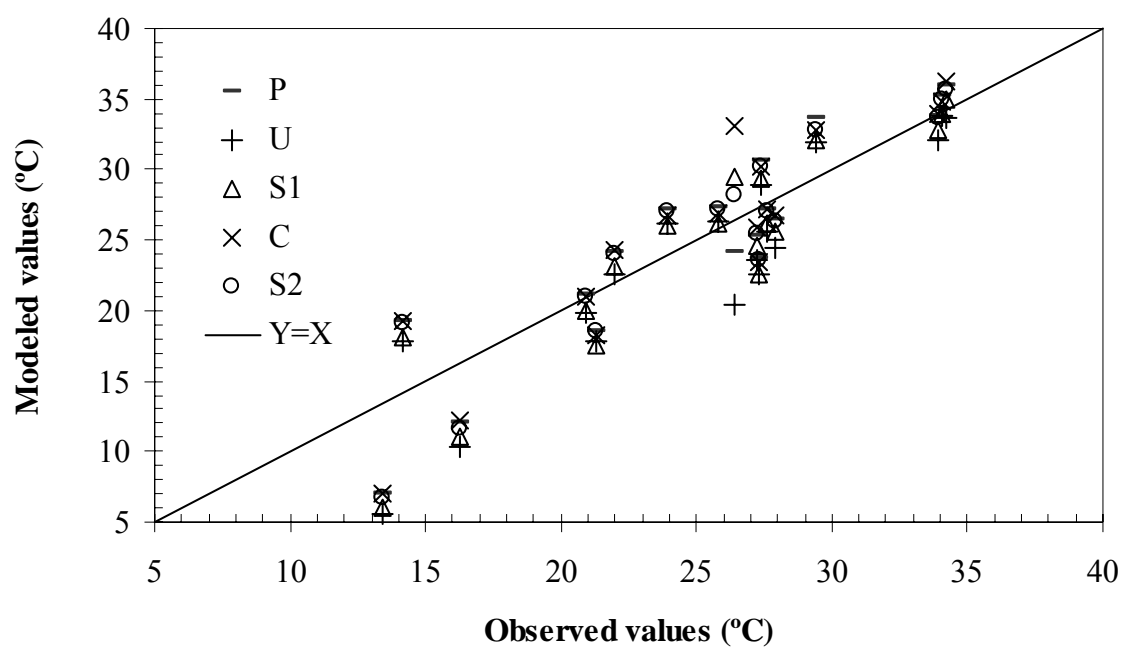

Figure 1. Modeled and measured soil temperature data. Solid line represents 1:1 ratio.

Table 2. Regression equations ( $\mathrm{T}_{\text {in situ }}=\mathrm{m} \mathrm{T}_{\mathrm{s}}+\mathrm{b}$ ) obtained between the values measured $\left(T_{i n}\right.$ situ $)$ and estimated $\left(T_{s}\right)$ for the soil temperature for each of the SplitWindow algorithms.

\begin{tabular}{cccccc}
\hline Algorithm & $\mathbf{b}$ & $\mathbf{~ m}$ & $\mathbf{r}^{2}$ & RMSE (\%) & P \\
\hline P & -3.31 & 1.13 & 0.8465 & 1.0182 & 0.0000 \\
U & -4.35 & 1.10 & 0.8254 & 1.1977 & 0.0000 \\
S1 & -4.30 & 1.14 & 0.8486 & 1.0551 & 0.0000 \\
C & -3.30 & 1.14 & 0.8319 & 1.1005 & 0.0000 \\
S2 & -3.45 & 1.13 & 0.8548 & 0.9959 & 0.0000 \\
\hline
\end{tabular}

decades. Several methods have been proposed. However, Split Window algorithms have the advantage to show a simple mathematical structure and, in many cases, only need the information from satellite.

The coefficients adjusted from the linear regression enable us to explain on $82.54 \%$ of the soil temperature variability. Algorithms used exhibit mean squared errors greater than $1 \%$, while that of Sobrino and Raissouni (2000) is 0.9959 $\%$. This error indicates the degree of overor under-estimation produced by the algorithm with respect to the average of the observed values (Rabat, 1995). Nevertheless, errors observed, are consistent with those reported by Galve et al. (2007) to compare different SplitWindows algorithms.

In our research, the corrections for water vapor tend to be irrelevant in statistical terms, although the importance of this parameter has been reported in other studies (Parra et al., 2006).

The used method has been validated by other authors from NOAA satellite images (Price, 1984; Sobrino and Raussoni, 2000), but data estimation is very sensitive to changes in soil coverage, 
so that these algorithms require that coverage uniform within the pixel soil as occurred in this application.

\section{CONCLUSIONS}

The analyses carried out show that the five studied algorithms generate results with no significant differences, either in the estimate or in the mean squared error. However, in terms of absolute values, the algorithm of Sobrino and Raissouni (2000) presents the lowest errors.

The results are satisfactory, although it is necessary to use more thermistors in order to better pixel representation and algorithms validation.

\section{ACKNOWLEDGEMENTS}

The principal author thanks MECE FRO Project 0309 of the La Frontera University, Chile, and grant Folio 24071079 of the CONICYT, for their support in carrying out this research. J.C. Parra and L. Morales are grateful for the financial support given for the project DI08-0029 of the La Frontera University.

\section{REFERENCES}

Caselles, V., Coll, C., Valor, E. 1997. Land surface emissivity and temperature determination in the whole HAPEX-Sahel area from AVHRR data. Int. J.Rem. Sens.18, 1009-1027.

Carlson, N., Ripley, A. 1997. On the relation between NDVI, fractional vegetation cover, and leaf area index. Rem. Sens. Env. 54, 313-323.

Galve, J. M, Coll, C., Caselles, V., Valor, E., Niclòs, R., Sánchez, J. M., Mira, M. 2007 Simulación y validación de los algoritmos de la temperatura de la superficie terrestre para los datos de MODIS y AATSR. Tethys 4, 29-34.
Morales, L., Parra, J. 2002. Estimating thermal infrared radiance emitted by the atmosphere using reanalysis data. Rev. Mex. Fis. 48, 119121.

Parra, J., Sobrino, J., Morales, L., Castellaro, G., Uribe, J., Gaete, N. 2006. Aplicación de un Algoritmo de Split-Window para la estimación de la temperatura de la superficie terrestre desde datos AVHRR-NOAA. Agric. Téc. 66 (4), 385392.

Prata, A., Platt, C. 1991. Land surface temperature measurements from the AVHRR. Proc. of the 5th AVHRR Data Users Meeting. June 25-28. Tromso, Norway, pp: 433-438.

Price, J.C. 1984. Land surface temperature measurements from the split window channels of the NOAA 7 AVHRR. J. Geophys. Res. 89, 7231-7237.

Rabat, P. 1995. Modelling and parametrization of the soil-plant-atmosphere system. Wageningen Press. Wageningen, The Netherlands, 513 p.

Rouanet, J. 1983. Clasificación agroclimática IX Región. Macroárea II. Investigación y Progreso Agropecuaria. INIA Carillanca 2(2):22-26.

Sobrino, J., Caselles, V., Coll, C. 1993. Theoretical split window algorithms for determining the actual surface temperature. II Nuovo Cim. 16, 219-236.

Sobrino, J.A., Raussoni, N. 2000. Toward remote sensing methods for land cover dynamic monitoring: application to Morocco. Int. J. Remote Sens. 21, 353-366

Sobrino, J., Jiménez, J., Paolini, L. 2004. Land surface temperature retrieval from LANDSAT TM5. Rem. Sens. Env. 90, 434-440.

Steel, R., Torrie, J. 1988. Bioestadística, principios y procedimientos. Mc Graw-Hill. New York, USA, $622 \mathrm{p}$.

Tosso, J. 1985. Suelos volcánicos de Chile. Instituto de Investigaciones Agropecuarias. Santiago, Chile, $723 \mathrm{p}$.

Ulivieri, C., Castronuovo, M., Francioni, R., Cardillo, A. 1992. A split window algorithm for estimating land surface temperature from satellites. Advances in Space Res. 14 (3), 59-65. 